\title{
Vientos de cambio en la Asamblea Mundial de la Salud 2007
}

\author{
Winds of change at the World Health Assembly 2007
}

Diego Bernardini*

\begin{abstract}
Resumen
Todos los años con la inauguración de la Asamblea Mundial de la Salud se esperan novedades, que no siempre llegan. Una nueva gestión comienza en la Organización Mundial de la Salud (OMS) y el tema de este año estará en las áreas de seguridad y regulaciones internacionales, sin pasar por alto la seguridad materno-infantil, las enfermedades no comunicables y la migración de los profesionales de la salud. En medio de estos eventos suele resultar útil la disección y el análisis de los discursos de los representantes de distintos países.

Este artículo presenta unas breves comparaciones entre las líneas políticas de países desarrollados y aquellos en vías de, pero con un denominador común, la cooperación internacional, sus distintas concepciones, la inversión estratégica o simplemente, solidaridad.
\end{abstract}

\section{Abstract}

Every year opening of the World Health Assembly arises expectancy of innovations, which not always occur. With a new leadership in the World Health Organization (WHO) the main issues this year are health security and international regulations, but not forgetting safe motherhood, non communicable diseases or migration of health workers. During the events of the Assembly, it turns out to be useful to analyze and compare speeches of different countries' delegates.

Here, short comparisons are presented between health policies of developed and developing countries, but with a common denominator being international cooperation and its different conceptions, strategic inversion or simply, solidarity.

Entre el 14 y el 23 de mayo de 2007 tuvo lugar la edición número 60 de la Asamblea Mundial de la Salud en la sede de Naciones Unidas. En Ginebra esta vez soplan vientos de cambio. Con un papel internacional recuperado de la Organización Mundial de la Salud (OMS) gracias a la anterior gestión de la Dra. Brundland y después de la corta y malograda función del Dr. Wook, la Organización se encamina, de la mano de su nueva Directora General, la Dra. Chan, a colocar sobre la agenda mundial el tema de la seguridad en salud.

Con la creación en el 2005 de la Comisión para el Estudio de los Determinantes Sociales de la Salud, la OMS dio un giro a la concepción de la salud, entendiendo que mientras siga habiendo personas que sufran amenazas o riesgos sociales y económicos, sus derechos fundamentales estarán amenazados. Asegurar ciertos mínimos y adecuados estándares para la promoción de la salud y la vigilancia de la enfermedad es la premisa. En consecuencia, mientras haya países cuya mayoría de la población pase penurias socioeconómicas, el resto del mundo también pagará sus costos, y lo hará en términos económicos, como lo subrayara la Comisión de Macroeconomía y Salud liderada por J. Sachs.

Sin embargo desde niveles más micro o más tangibles y concretos si se quiere, esta seguridad en salud está pasando desde una concepción basada en las prestaciones o cuidados institucionales, hacia la concientizacion y la conducta personal. Los estilos de vida de las personas son, claramente, quienes dictan la evolución en salud desde la perspectiva de curso de vida. En esta perspectiva encontraremos personas sanas con capacidad de trabajo funcional a edades avanzadas o personas de edad joven pero con capacidad funcional envejecida y alta demanda de servicios de salud a edades más tempranas de la esperada.
Resultó muy interesante el ejercicio de comparación entre los discursos de los delegados de países desarrollados como Suecia o Finlandia en relación a algunos más cercanos a nuestra realidad. En los primeros, lo que se repetía era perspectiva de género e igualdad de oportunidades, educación, enfoque multisectorial de los problemas de la salud y construcción de capacidades en todos los niveles de decisión política. También se mencionó la posible pandemia de influenza humana y con ello, la cooperación internacional.

Durante su discurso, ante la Asamblea, el ministro Ginés González García sostuvo que "la cooperación resulta fundamental para forjar un porvenir más seguro". Sin embargo cuando se habla de cooperación siempre nos viene a la memoria el eje norte/sur. El error de los donantes de este tipo de "cooperación" es que suelen subestimar y quedar fuera de foco o no coordinados en tiempo y en espacio con el receptor. La cooperación sur/sur es fundamental. ¿Acaso no existe la cooperación norte/norte? Tailandia e Indonesia han establecido un sistema de colaboración luego de su experiencia con la gripe aviar, un caso concreto y reciente de colaboración sur/sur. Brasil y Argentina tienen un camino recorrido muy importante en su lucha contra la propiedad intelectual de las patentes de medicamentos y lo están demostrando con ejemplos muy concretos.

Hoy la salud es solidaridad, como lo fue en el momento de la Constitución de la Organización Mundial de la Salud en 1948. Solidaridad del rico con el pobre, del joven con el viejo, entre lo público y lo privado, del norte con el sur, pero también del sur con el sur y sobre todas las cosas, solidaridad entre todos.

Referencias

1. $60^{\mathrm{a}}$ Asamblea Mundial de la Salud. Disponible en URL: http://www.who.int/mediacentre/events/2007/wha60/en/index.html

*Médico. Master por la Universidad de Salamanca, España. Interno - OMS/ WHO, Ginebra. diegobernardini@usal.es 